\title{
The Becoming of the Scholarly Editor
}

\author{
Reading Paul Eggert's The Work and \\ the Reader in Literary Studies
}

\author{
Matt Cohen
}

\begin{abstract}
Paul Eggert's The Work and the Reader in Literary Studies makes an important intervention in textual scholarship by redefining scholarly editions as functions of a process enacted in dynamic relation to an idea of a work on one hand and imagined readers - including the author as a first reader of drafts - on the other. This essay responds to The Work and the Reader by pursuing the definition of the "reader" toward a rethinking of edition-making as both a material and an ethical practice.
\end{abstract}

$\mathrm{P}$ Aul Eggert's The Work and the Reader in Literary Studies triangulates the practices of reading, editing, and researching the histories of books to show how the concept of the literary "work" has survived poststructuralism. This ambitious study begins by observing that the concept of the "social text" innovated by D.F. McKenzie and Jerome McGann offered a new book history and new means of interpretation, but these in turn did not generate a new conception of the "work" that could ground a change in editorial practices. Because audiences - their postmodern condition notwithstanding - expected a clear reading text in every edition, centering the multiplicitous witnesses of a work or decentering its author could only go so far. And so, Eggert concludes, the "supposedly social-text edition is actually a form of versional editing that is claimed to have dispensed with intention but is forced to smuggle it in by the back door whenever the way forward gets difficult" $(2019,99)$. Eggert sets himself the task of revealing how the work haunts the edition and how, in a world in which digital editing is increasingly the norm, editors might run at, rather than from, the complexities of their dependence upon readers. In doing so, they might indulge in a new relationship between bibliography and book his- 
tory, rethink authority and intentionality as dimensions of editorial production, and, as a result, save the scholarly edition from a slow demise.

The editors of a work implicate readers in every act of textual recovery. "Every emendation, every regularisation, every instance of modernised spelling admits this unavoidable reality", Eggert insists, "that the needs of the readership are being anticipated and incorporated - showing that there is no securely external position for the editor or the edition" (2019, 7). In their turn, in the act of recovering or transmitting a work from the past, "professionals orchestrate the terms of the transaction according to the slowly changing tenets of their practice. The concept of the work happens to provide a convenient conceptual organisation for those activities" $(2019,31)$. Before the digital age, whether you were from the German or the Anglo-American school of scholarly editing or just a happy-go-lucky bowdlerizer, the limitations of the book format, publishers' financial considerations, and readerly comfort with textual interfaces shaped how you made your edition. In an age in which editions are built upon extensive archives of digital surrogates - images of primary documentation accessible to readers in unprecedented ways - some pressures have changed, but much remains the same.

I like Eggert's both-and attitude about this situation: if we think of an edition as an argument, a work as a phenomenon rather than just an idea, and the digital medium as an opportunity for dialogic relations between archives and editions, then we can have texts but also authors, books but also works, book histories but also close readings, authorial intentions but also divergent readings of those intentions. What The Work and the Reader presents is less the theory of the work Michel Foucault called for than, sensibly, strategies for dealing with the work's impossibility as a unity. ${ }^{1}$ Eggert confesses that the task of the "literary-inflected, work-oriented book history" he envisions may be too broad to be tackled fully by the approach he takes in this study $(2019,94)$. Of course it is, so here I offer a brief thinkingthrough of some of that approach's assumptions and its perhaps necessary exclusions toward, if not a definition of the work, a breadth of mind about how to bring history into relation with interpretation in the act of editing. To this end, I first consider what is meant by "the reader", and then suggest that a confrontation with the limits of anticipating a reader has consequences for thinking about both what an edition might be and what is embraced by our understanding of the scholarly editor's duties.

1. See Foucault 1998. 


\section{Being a Reader}

Eggert opens with an eloquent account of his absorptive experience of reading a scholarly edition, an account that underwrites his later emphasis on providing a good reading text in every edition. I was struck, however, by how different his ideal reading experience is from mine. He calls that feeling a "spell" - and I agree that many people feel it that way, too (2019, 3). But it is seldom like that for me. It's more often a struggle, Jacob versus the Angel, slowly realizing the supernatural force of the text, but persevering anyway. Reading is less painful for me than, apparently, writing was for Joseph Conrad, in Eggert's account. But there are works, famous for their absorptive qualities, that I read at about the same pace at which Conrad wrote, four pages a day at best, and happily so. Coming out of a reading jag is for me often not so much like a hypnopompic state as a form of relief, or at other times like slight nausea after a long run. So theorizing the reader of an edition for me means not starting with a common absorptive or attentive state we hope readers can still achieve through the digital medium, but something different: a sense that both medium and reader adjust, that maybe even new moods, new "feels" as the kids say, might characterize some readers' experiences.

Because readers have agency, and because the author of a work is always a reader, too, "readers must [. . .] be built into the work-concept; they lend the work power" $(2019,93)$. Even as original drafts leading to and instances published of a work persist for the editor to analyze, readership shifts, shaping how editors imagine a work's coherence for a new audience. The work is thus not a transcendent thing, but a temporal, historical phenomenon. Challenging though it is to implement, this conception puts pressure in healthy ways on the assumptions that editors have made about the audiences for their editions and the way they study the historical development of the works argued by those editions. And I agree with Eggert's insistence that in the evolution of the scholarly editing of literary works to an online format, both the role of scholarly editions and the lived relevance of literary studies are at stake $(2019,94)$. The implicit insight that drives Eggert's readings of editions is not just that every edition makes an argument about the work being edited, but that each makes at the same time a claim about the theory and practice of editing. The attempt to enfold editorially acts of reading into the "coming-into-being of the work" is daunting to imagine in theory or as a definition of what gets edited, but Eggert's insistence on a pragmatic approach — always keeping a potentially broad readership of 
the edition in mind, always considering the author as the first reader (and consequently editor) of her own drafts as you work on establishing a version history - offers comfort in its turn $(2019,176)$.

Well, it comforts this reader, anyway. Sometimes in the argument - as when reading is described as "constitutive of text" - it feels a bit as if what Eggert means by reading is the aggregate linguistic comprehensibility of a text in any given historical moment; something like Saussure's langue. Text as "experienced meaning" or "dimension", Eggert's focus, goes beyond just the intelligibility of language, but it is also, as he points out, constrained by it $(2019,173)$. To me this kind of moment points to a fundamental tension in The Work and the Reader. It exhibits an urge to define things, to say an edition is this or that, that "editions will be identifiable as such" because of certain properties or activities. And yet, it wants at the same time to think of these definitions as resting upon not facts, but arguments; on "impulses" rather than ideas $(2019,83)$. This move is provocative, but it has the effect of constraining us to a conversation that comes back to some concrete requirements: scholarly editions represent a work, present an analysis of known data relating to it, and make a coherent argument about what a reading text of that work should look like. They are created by editors, who are recognizable as such because they wield critical judgment. The reader, in the end, is a kind of vague factor, a pole around which the evolution of the edition, but not the necessarily the editor, happens.

But what if there is no "reader", only readers? It could be argued that, given that there was no golden age in which millions of people could be counted upon to buy and read most scholarly editions, there is no "reader" of scholarly editions. There are certainly readers, and in this case we are for the most part, to paraphrase Michael Warner, a historically unusual sort of people. ${ }^{2}$ Eggert tells us that "ordinary readers" are our audience, because few are the hardy souls who will want, for example, to look at every manuscript of Whitman's Leaves of Grass $(2019,90)$. Were scholarly editions of the past meant for "ordinary readers"? Are most digital scholarly editions so meant? Is it time to give up the moniker "scholarly edition" entirely, not because we don't value our expertise, experience, and judgment, but because we need to begin weaving a new relationship with ordinary readers - one in which we do not describe them as "ordinary"?

2. WARNER 2004, 36 . 


\section{Editing Emergence}

The Work and the Reader is persuasive in asking us to think about a digital edition as making "an argument about the contents of the archive of the work, not as somehow its highest culmination or as its teleologically preordained fate" $(2019,76)$. Not least among the advantages of this are that "newly emerging literary-critical emphases and significances will be [. . . ] addressable from within the edition" and that the success of the textual editing, as compared to the archival facsimiles, will be measurable by access statistics $(2019,76)$. I would add to this that such an editorial stance and such an attention to the demands of archiving will also render editions with the flexibility to add new archival materials when they are discovered; the challenge then is not to build an interface so wedded to the original argument about the contents of the archive of the work that the argument itself cannot be altered in the light of new evidence. ${ }^{3}$

Still, these assertions about the argumentative quality of the edition and the flexibility of digital ones may constrain us in some ways. At times, The Work and the Reader is defensive about the definition of the scholarly edition. Scholarly editing is "a more profoundly critical activity" than social editing, for example; Edward Vanhoutte's definition of a scholarly edition as "one whose established text is automatically linked to its sources in a complete digital record of the textual history of the work" ignores, Eggert says, "the edition's essential characteristics of critical judgment and persuasiveness". ${ }^{4}$ I am not sure either of those assertions is necessarily true - perhaps judgment and persuasiveness are necessary in the creation of a coherent archive, and perhaps the definition of "critical" is not solely in the hands of scholars, but in the hands of the people as well. But in any case such assertions limit rather than expand the remit of scholarly editing and do so at a time when we may desperately need to be rethinking what an editor does or what can be recognizable as a form of judgment. To make "users" or "contributors" into "readers" and "editors" in the case of a social edition might require a different sort of judgment than that required to assemble arguments about textual cruxes, but it is still judgment.

"Each scholarly edition [should] be understood as an argument", Eggert insists, "embodied in the reading text and apparatus, about the textual materials relevant to the work being edited" $(2019,5)$. Yet at what point

3. See, however, my caveats about using access statistics to assess editions in Cohen 2017, 187-209.

4. Vanhoutte is paraphrased in EgGert 2019, 78. 
does one execute the operation of "understanding" in finding out the argument of an edition? If we amplify the sense of "plot" in the word argument, perhaps we can take a step toward the peculiar condition of the digital edition: like physical ones, the conditions of legibility shift around a digital edition, but unlike books, digital editions also change. A correlate of this, which I would argue applies retrospectively to some printed editions as well, is that the unity of intention discoverable through the operation of understanding an edition as an argument is useful only insofar as we recognize it as an illusion created by the premise that there is one argument being made, rather than many, or rather than one being attempted and undermined by another, and so on. As Eggert observes, in the social-intellectual activity of putting together a digital edition, the same dynamics of editorial differences of opinion hold as in a collaborative printed edition. Likewise, just as in a printed edition typesetters, binders, and designers help construct that argument, the same is true of the fabricators and transmitters of electronic editions. But what differ are the expandability, transformability, and unique forms of accessibility of the digital edition. By the latter of these I mean that you may come to an edition from any number of different paths that frame the text differently, not least of which is Google's fantastic illusion of a universal information access portal - those modes of access, including physical devices, are also not external to digital editions as they are perceived by readers.

"We must ask", says Eggert, "what is the thing [that we read] and how may we pursue a distinctly literary study of it even as we cohabit the field in which it exists" $(2019,11)$ ? As I see it, a distinctly literary study is unnecessary, perhaps impossible, though I find Poe-like pursuits of it fascinating. But what if we regard as not just possible but potentially illuminating the idea that an edition exhibits heterogeneous arguments (and not just the poststructuralist ones that undermine a main argument and thereby constitute it)? Eggert trenchantly notes that "a transcription using an encoding scheme models, in a simplified form, what is, in reception, a more complex phenomenon" - a rich example of the minima moralia to be found throughout the pages of The Work and the Reader $(2019,73)$. But an edition might use not just multiple encoding schemes, but more than one underlying data model, as the Whitman Archive does (at the moment, at least). Different editors with different intentions and even competing ideas about what constitutes a Whitman "work" have built the different parts of the Whitman Archive. We have a plan to link all known versions of a work using an array of identifiers, but at this point the technical implementation of that plan is still a work-in-progress: a kind of neutral ground, rather 
than an authority, in which what counts as a "work" is still shifting and at times contested among the contributors. I think that keeping in abeyance the grand-scale development of an argument that the Archive might convey has been one of the more generative stances we have taken as a group - along with agreeing to do whatever necessary to keep the edition open access. Certainly it can be claimed that in doing so, we are making any number of arguments, as reactions by our readers and reviewers testify. "The extent to which 'coherence' is a necessity in a volume on Whitman may itself be a point of contention", as the inimitable Jay Grossman once wrote. $^{5}$

The relationship between documentary metadata and published editorial apparatus can be, in a digital edition-in-progress, one of the sites for the emergence of a range of arguments. Eggert asks us to visualize the relationship between the documentary layer of editions and their editorial components as being on a "slider" not of roles or procedures but "impulses": the archival-editorial impulses always overlap but represent different kinds of labor $(2019,87-8)$. Yet the object of this visualization is to make clear how editing is different from archiving. Archival labor — and here Eggert speaks metaphorically, referring to the work of an edition's image processors, transcribers, and encoders - is not critique, Eggert suggests, and does not face the reader; editorial labor involves judgment, intervention, and reader-oriented framing of a work. His description of the relations between these two impulses, however, leaves out the crucial steps of establishing and recording metadata. Metadata is, like the selection of candidates for versions of a work, a pivot between the roles of archivist and editor, because metadata is where the archivist directs attention to readers and where the editor posits identities for documents that will affect metadata generation. Archivists do not commonly transcribe documents: they assess them, and then they create metadata describing them. Put in TEI terms, the "slider" concept focuses on the body of the TEI file, not on its header, where archival and editorial labors - not just impulses - mingle.

In my experience, image processors, transcribers, and encoders can barely get started until they know something of what an editor plans to argue about a document set. There is an iterative tendency whereby, first, longstanding shared assumptions of readerly practice (what counts as a transcribable mark?) and editorial practice (of course all paragraphs and stanzas are tagged) are employed in the act of transcription; and then

5. Grossman 1993, 156. For a range of claims about the argument being made by the Walt Whitman Archive, see Stally brass, et al. 2007. 
either a transcriber or encoder has to demand clarification (did Dickinson mean this as a paragraph, a stanza, or something for which we have as yet no name?) or an editor has to turn archivist and make the changes herself once the editorial logic has been more fully established. Archives, like editions, anticipate audiences, mediate between documents and those audiences, and make arguments. As such, cannot archives be critical in themselves?

The metadata layer offers challenges to the dream of interoperable editions. The Work and the Reader relies, for the fulfillment of its vision of unitary archives that can underlie multiple editions, on a metadata layer that has often proven less tractable than one might hope. A digital edition can be built entirely, through application programming interfaces (APIs) or other means, on top of someone else's, or several others', digital archival work. (There are surely Borgesian editions only legible to other machines through an API.) But if archival metadata has been built with a previous editor's notion of what constituted the work, and you are not in agreement about the work, then you have to re-do the metadata in the archive. The permeability of the editorial and archival activities when they have developed as a function of determining the editorial argument means reduced flexibility for those who do not agree with that argument.

What's more, in active projects, metadata shifts in ways that complicate extramural editorial efforts that rely on their archives. At the Whitman Archive, we often return to manuscripts in order to try to date them and realize that if we decide they led to one work (of which we have made an edition already) then they carry one date, but if they led to another (which we are subsequently trying to edit), they appear elsewhere in the manuscript chronology. And because Whitman had a number of works - which he often called "spinal ideas" - that never saw publication, threaded throughout his manuscripts are traces of poems that emerge, become prose, return to poetry, change titles, dissipate into two or more other poems, or merge with other spinal ideas. Certainly in the edition's archival layer metadata you can designate that a document participates in more than one work's version history. But if another editor cannot adjust the metadata in your archive, she cannot make an editorial argument whose consequences will reach all the way down to the basic infrastructure of the document set. Subsequent editions, if not performed in collaboration with the generators of the archive, will remain superstructural with relation to the primary

6. See Trouillot 1995 and Stoler 2009; and on metadata ethics, see Pomerantz 2015, Sacco, et. Al., 2015, and Wilson and Alexander 2016. 
data. And that means that editorial ethics, not just cruxes, APIs, and readers, must be considered as part of an understanding of what constitutes an edition.

\section{Being and Editing}

"A keener understanding of what, at the moment, is frustrating the development of the traditionally more ambitious editions of multi-witness works is needed", Eggert writes $(2019,81)$. Those forces include the market forces discussed early in The Work and the Reader, and they include the ability to embed complex editorial decisions in TEI or other kinds of encoding, while "showing" only a subset of those by way of the interface. But they also involve a shift in what people can imagine doing with an edition now that a scholar need not bow to publishers' cupidity, traditional-canonical necessity, the fantasy of an Oxbridge temporality (definitive for a thousand years), and the limited audience of the academy, among other previous pressures. Moreover, many graduate students do not see a scholarly, or at least professorial, career at the end of their doctoral experience. So they are making editions that are scholarly, in that they involve careful judgment, painstaking research, and the consultation of multiple sources, but that are not designed to produce a professional scholar along with, and as a function of, a scholarly edition. And I have heard many young builders of archives and editions ask us to think of our archivists - transcribers, encoders, image processors - and interface designers as co-editors, in an effort to break down the service hierarchy (often a gendered one) that has long haunted edition-making. This is timely during the often-destructive age of mass digitization, for if editors carry texts from the past into the future, translating them for new readers, the editorial projects in the course of their historical research generate people who themselves become knowledge archives of past textual forms, technologies, and ways of reading.

In this and other ways, The Work and the Reader's inspirational attention to process and to reimagining editing in a variety of ways seems to me to justify a similar expansion of our discussion of editorial theory and practice to a consideration of the stakes of doing this kind of work, beyond literary recovery or defending scholarly expertise. The audience for books (digital, audio, physical) is growing; the scholarly audience for canonical literary scholarly editions is shrinking. More students, fewer professors, more contingent laborers in the classroom: all of this adds up to a situation in which it is a truly heroic, longue-durée, or foolish exercise to sink money and effort into a printed scholarly edition that doesn't speak to something of immedi- 
ate public import. If your scholarly edition makes the lives of adjuncts or lecturers easier, it could garner a broad academic readership; but to do so, it might have to be free or easily piratable. Yet market considerations aside, the making of a scholarly edition can be an occasion for strengthening community and educating students.

The Work and the Reader helps us appreciate the fascinating new ecology in which editors labor. The Rossetti Archive wasn't meant to be widely adopted; it was an act of editorial theorizing and a proof of concept. The Whitman Archive was meant to be widely adopted, and after twenty-five years has only begun do the kinds of acrobatic things Hans Walter Gabler did with James Joyce. How Radical Scatters handled Dickinson and what the renovated Charles W. Chesnutt Archive will do are widely different. To me, it is the fecundity both in intellectual and marketplace terms of what Ted Striphas calls the "late age of print" that mark this moment in editorial history. I am not the only scholarly reader who has ordered a facsimile edition from one of the parasitical digital print-on-demand sellers out there, just because it is well-nigh impossible to find, for example, affordable editions of Ernest Hello's works in English and I can't read them online because they are too long and I can't print them out because my austerityridden department charges us for our printer usage. The politics of scholarly editions operate beyond the realm of representation on the syllabus or the profession, in the financial dynamics of the classroom, the department, the university library, and the administrative hiring plan for tenure-line faculty. And there are tremendous opportunities to do good things as editors, perhaps especially in a tumultuous time.

Lately I have been trying to think about what kinds of judgment beyond the textual might be woven into my daily editorial practice, to do the best I can to make good choices as a project director. My partial, drafty editorial principles (frankly adapted from the Hippocratic Oath and the Colored Conventions Project) are, so far:

- First, to do no harm;

- Second, to remember always that editing is not a science;

- Third, and also, to remember that all acts of editing are shared acts, partaking of the ethos of teaching and learning; and

- Fourth, consequently, to give all credit where credit is due.

It is evident that these say nothing specifically about method or procedure, though in practice I draw on many scholars' lists of these (never trust a title page; in the archives, things become detached and reattached; more 
spreadsheets, fewer stylesheets; ask yourself if you really need TEI; with great scripting power comes great responsibility; and so on). But the standards I want my colleagues to hold me to include these four, which are as difficult to maintain as any methodological relationship to variants, accidentals, or encoding schema. Indeed, the first principle is almost impossible to uphold, and certainly so if one thinks the only harm an editor can do is to an author's work, reputation, or intention. Working with African American and Native American materials involves bridging the community ethics of the academy and those of the people generating and preserving the documents, and this changes both the purposes for and the pace at which archives and editions develop. Sometimes the best thing to do in the case of a certain edition is not to make one. Better to postpone an edition than create it without a descendant community's uses and protocols in mind; better to do so than merely to put in a single note in the acknowledgments in the back of the book, rather than naming as co-editor, that graduate student who made the pivotal discovery or painstakingly brought the data to coherence.

"The test of a good edition is whether it manages to change the way in which the work is understood", Eggert insists $(2019,144)$. The same is true of good book history. This formulation inspires me as it steers away from definitiveness, leaving healthily vague the question of who is doing the understanding. That opens the door to judging editions by their effects rather than their methods, their hewing to scholarly standards of the day (for they are always of a day), or their politics. And when you consider Paul Eggert's contributions to the institutional life of textual scholarship, to students and postdocs and readerly communities of many kinds, and to many an author's literary afterlife, The Work and the Reader in Literary Studies appears as yet another exemplary expression of the becoming-editor.

University of Nebraska-Lincoln

\section{Acknowledgments}

My thanks to John Young for including me on the panel for which these remarks were originally prepared, and to Textual Cultures editor Marta Werner for her generosity in including us in this issue. As always I am indebted to Nicole Gray, Ken Price, Ed Folsom, and my collaborators at 
the Walt Whitman Archive and the Charles W. Chesnutt Archive, not just for thinking these matters through but for living them in our work. Former students have deeply shaped this essay: Micah Bateman's work on poetry's circulation in social media, Molly Hardy's on bibliographical metadata in archival settings, and Hannah Alpert-Abrams's on ethics in the academy all show their effects here.

\section{Works Cited}

Browner, Stephanie, Matt Cohen, and Kenneth M. Price, eds. 1997-2021. The Charles W. Chesnutt Archive @ https://www.chesnuttarchive.org/.

Cohen, Matt, Kenneth M. Price, and Ed Folsom, eds. 1995-2021. The Walt Whitman Archive @ https://www.whitmanarchive.org/.

Cohen, Matt. 2017. Whitman's Drift: Imagining Literary Distribution. Iowa City: University of Iowa Press.

Colored Conventions Project. 2012-2021. @ https://coloredconventions.org/.

Eggert, Paul. 2019. The Work and the Reader in Literary Studies: Scholarly Editing and Book History. Cambridge and New York: Cambridge University Press.

Foucault, Michel. 1998. "What Is An Author?" In Aesthetics, Method, and Epistemology, edited by James B. Faubion, 205-22. Translated by Robert Hurley and Josué V. Harari. New York: The New Press.

Grossman, Jay. 1993. "Review of Robert K. Martin, ed., The Continuing Presence of Walt Whitman: The Life after the Life". Walt Whitman Quarterly Review 10.3: 154-60.

Joyce, James. 1986. Ulysses, edited by Hans Walter Gabler. New York: Vintage.

McGann, Jerome J., ed. 2000-2021. The Complete Writings and Pictures of Dante Gabriel Rossetti. @ http://www.rossettiarchive.org/.

- 1991. The Textual Condition. Princeton: Princeton University Press.

McKenzie, D[onald]. F[rancis]. 1986. Bibliography and the Sociology of Texts. The Panizzi Lectures, 1985. London: The British Library.

Pomerantz, Jeffrey. 2015. Metadata. Cambridge, Mass.: MIT Press.

SAcco, Kathleen L., et. al., eds. 2015. Supporting Digital Humanities for Knowledge Acquisition in Modern Libraries. Hershey: IGI Global.

Stally brass, Peter, et al. 2007. "Responses to Ed Folsom's 'Database as Genre: The Epic Transformation of Archives”. PMLA 122.5: 1580-1612.

Stoler, Ann Laura. 2009. Along the Archival Grain: Epistemic Anxieties and Colonial Common Sense. Princeton: Princeton University Press.

Striph as, Ted. 2009. The Late Age of Print: Everyday Book Culture from Consumerism to Control. New York: Columbia University Press.

Trouillot, Michel-Rolph. 1995. Silencing the Past: Power and the Production of History. Boston: Beacon Press.

Warner, Michael. 2004. "Uncritical Reading". In Polemic: Critical or Uncritical, edited by Jane Gallop, 13-38. New York: Routledge. 
Werner, Marta, ed. 2013. Radical Scatters: Emily Dickinson's Late Fragments and Related Texts, 1870-1886. @ http://radicalscatters.unl.edu/.

Wilson, Emma Annette and Mary Alexander. 2016. "When Metadata Becomes Outreach: Indexing, Describing, and Encoding For DH”. DH + Lib. @ https://acrl. ala.org/dh/2016/07/29/when-metadata-becomes-outreach/. 